\title{
DER STALINISMUS UND DIE RENEGATEN
}




\section{Der Stalinismus und die Renegaten}

Die Literatur der Exkommunisten 
für Gunther R. Lys

Die Deutsche Bibliothek - CIP-Einheitsaufnahme

Rohrwasser, Michael:

Der Stalinismus und die Renegaten : die Literatur der Exkommunisten / Michael Rohrwasser. - Stuttgart : Metzler, 1991 (Metzler Studienausgabe)

ISBN 978-3-476-00765-0

ISBN 978-3-476-03365-9 (eBook)

DOI 10.1007/978-3-476-03365-9

Dieses Werk einschließlich aller seiner Teile ist urheberrechtlich geschützt. Jede Verwertung außerhalb der engen Grenzen des Urheberrechtsgesetzes ist ohne Zustimmung des Verlages unzulässig und strafbar. Das gilt insbesondere für Vervielfältigungen, Übersetzungen, Mikroverfilmungen und die Einspeicherung und Verarbeitung in elektronischen Systemen.

(C) 1991 Springer-Verlag GmbH Deutschland

Ursprünglich erschienen bei J. B. Metzlersche Verlagsbuchhandlung und Carl Ernst Poeschel Verlag GmbH in Stuttgart 1991 


\section{INHALTSVERZEICHNIS}

I. Einleitung: Aspekte der Renegatenliteratur . . . . . . . . . . . . . 1

1. Umrisse des Themas . . . . . . . . . . . . . . . . . . 1

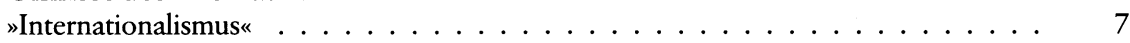

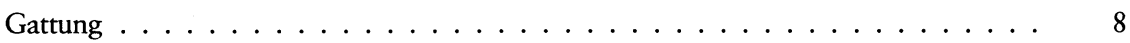

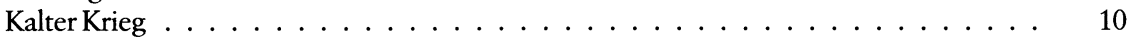

Renegatentadel-Renegatenlob . . . . . . . . . . . . . . . . . . . 14

2. Leitfaden und Aufbau der Arbeit . . . . . . . . . . . . . . . . 19

II. Wörterbuch derVerdammungen . . . . . . . . . . . . . . . . 26

1. Renegaten, Dissidenten und Konvertiten . . . . . . . . . . . . . . 26

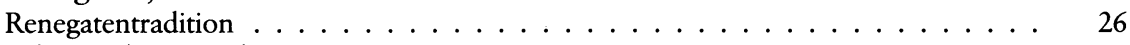

Exkurs: Adrien Turel . . . . . . . . . . . . . . . . . . . . . . . 28

Der Intellektuelle als Ketzer und Verfolger . . . . . . . . . . . . . . . . . 29

Literaturgeschichtsschreibung . . . . . . . . . . . . . . . 32

Der Renegat als»Triumph des Stalinismus«? . . . . . . . . . . . . . . . 33

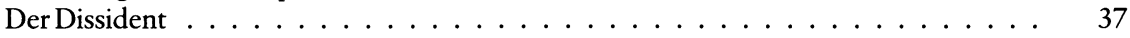

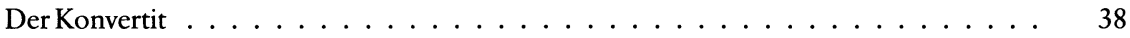

Apostat und Proselyt . . . . . . . . . . . . . . . . . 39

2. Ketzer, Deserteure und Verräter . . . . . . . . . . . . . . . . . . . 40

Häresie und Ketzerei . . . . . . . . . . . . . . . . . . . . . 41

Kirchen- und Parteigeschichte . . . . . . . . . . . . . . . . . 42

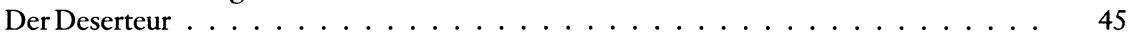

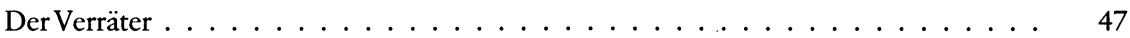

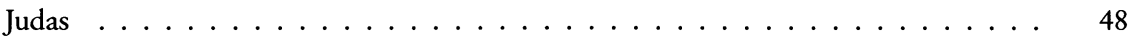

Zur Figur des Renegaten in der sozialistischen Literatur . . . . . . . . . . . . . 52

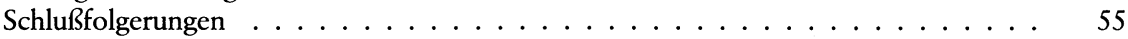

III. Der Spanische Krieg und die "Geburt des Renegaten" - Krivitsky, Regler, Kantorowicz, Koestler. . . . . . . . . . . . . . . . . 58

1. Faszination und Ernüchterung im Spanischen Krieg . . . . . . . . . . . . . 58

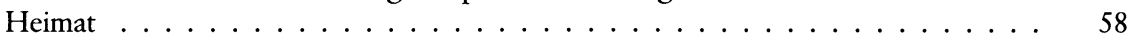

Medien und Propagandakrieg . . . . . . . . . . . . . . . . . . . . . 59

Madrid und Moskau . . . . . . . . . . . . . . . . . . . . . 62

Die Fünfte Kolonne . . . . . . . . . . . . . . . . . . . . 67

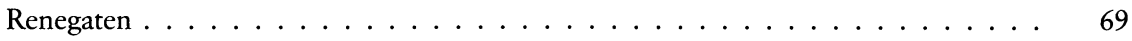

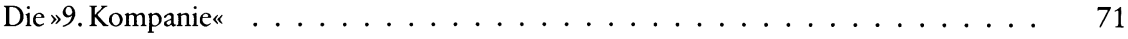

2. Walter Krivitsky: Opfer und Täter . . . . . . . . . . . . . . . . . . . . . . . . . . . . . . .

3. Die Geburt des Renegaten« . . . . . . . . . . . . . . . . . . . 81 
Gustav Regler: Lösung von der Partei und Denunziation ～. . . . . . . . . . . . . . 81

Gustav Regler: »Doppelagent" und Gedankenattentäter . . . . . . . . . . . . . . . 86

Die Verspätungen des Renegaten . . . . . . . . . . . . . . . . . . . . . 88

Liebe und Tod . . . . . . . . . . . . . . . . . . . . . . . . . 91

Die Geburt . . . . . . . . . . . . . . . . . . . . . . . . . . . . 94

Denunziation und Verfolgung . . . . . . . . . . . . . . . . . . . . 96

Anhang: Die Funktionalisierung im Nationalsozialismus _ . . . . . . . . . . . . . 101

IV. Alfred Kantorowicz und das»Tagebuch $\ldots \ldots \ldots \ldots \ldots$. . . . . . . . . 105

Der Weg in die KPD: Von der Elite zur Avantgarde . . . . . . . . . . . . . . . . . 106

Kantorowicz in der DDR . . . . . . . . . . . . . . . . . . . . . . 110

Korrekturen an den Tagebüchern? . . . . . . . . . . . . . . . . . . . . . . . . 113

Die Kritik in den Tagebüchern . . . . . . . . . . . . . . . . . . . . . . . . . . . . . . . 119

Der Funktionär und der Tagebuchautor . . . . . . . . . . . . . . . . . . . . . . 121

Die Sprache des Opfers . . . . . . . . . . . . . . . . . . . . . . . . 123

Das Niemandsland . . . . . . . . . . . . . . . . . . . . 126

V.Schauprozesse und Hitler-Stalin-Pakt . . . . . . . . . . . . . . . . . . 129

1. Die Polarisierung . . . . . . . . . . . . . . . . . . . . . . . . . . . . . . . . 129

Kritik, Apologie und Verdrängung . . . . . . . . . . . . . . . . . . . . . . . . . . 129

ManèsSperber und die Schauprozesse . . . . . . . . . . . . . . . . . . 132

Zweifel und Rückzug . . . . . . . . . . . . . . . . . . . . . . . . 135

Das Argument vom Zeitgewinn und die Hoffnung auf Krieg . . . . . . . . . . . 137

Spaltung . . . . . . . . . . . . . . . . . . . . . . . 141

Karikaturen der Kritik (Brecht und Bloch) . . . . . . . . . . . . . . . . . . . . . . 144

Folter und Erpressung . . . . . . . . . . . . . . . . . . . . . . . . . . 146

NS- und Sowjetjustiz. Stalin als Chirurg . . . . . . . . . . . . . . . . . . . . 147

2. Feuchtwanger, Brecht und Bloch . . . . . . . . . . . . . . . 151

Lion Feuchtwanger . . . . . . . . . . . . . . . . . . . . . . . . . . 151

Alfred und Heinrich Kurella. Die Frage der Denunziation . . . . . . . . . . . . . . . . 157

Bertolt Brecht und die Schublade des Schreibtisches . . . . . . . . . . . . . . . 160

Ernst Bloch:Stalin als Steuermann . . . . . . . . . . . . . . . . . . . . . . . 167

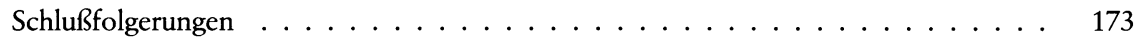

VI. Richard Krebs: Der Kominternagent _ . . . . . . . . . . . . . . . . . 177

1. Eine politische Karriere . . . . . . . . . . . . . . . . . . 178

2. Absprung von der Partei. Die Ankunft in den USA . . . . . . . . . . . . . 182

"American Mercury" . . . . . . . . . . . . . . . . . . . . . . 184

Themenverschiebung? . . . . . . . . . . . . . . . . . 186

3. Die Rezeption in den USA . . . . . . . . . . . . . . . . . . . . . . . . 188

Der Erfolg . . . . . . . . . . . . . . . . . . . . . . . 188

Der Autor und seine Glaubwürdigkeit . . . . . . . . . . . . . . . . . . . . . . . . . 189

"Counterattack« . . . . . . . . . . . . . . . . . . . . . . 193

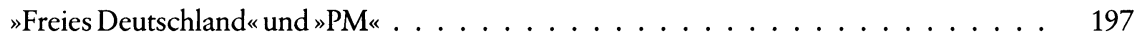

Exkurs: Der Fall Kravchenko ． . . . . . . . . . . . . . . . . . . . . . . . . . 199

Karl Korsch . . . . . . . . . . . . . . . . . . . . 200 
4. Krebs in den USA. 1941-1951 . . . . . . . . . . . . . . . . . . . . 204

Die Aussage vor dem "Dies-Committee

Nachkrieg . . . . . . . . . . . . . . . . . . . . . . . . . 207

5. Rezeption nach 1945 in Deutschland, Frankreich und Dänemark . . . . . . . . . 210

Richard Jensens Antwort an Krebs . . . . . . . . . . . . . . . . . . . . 211

Die westdeutsche Rezeption . . . . . . . . . . . . . . . . . . . . 214

6. Analyse . . . . . . . . . . . . . . . . . . . . 217

Glaubwürdigkeit der Einnerungen . . . . . . . . . . . . . . . . . . . . 217

Abenteuerroman, Thriller, Kriminalroman . . . . . . . . . . . . . . . . 224

Pseudonym und Wiedergeburt . . . . . . . . . . . . . . . . . . . . . . 225

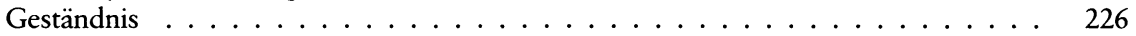

VII. Robert Bek-gran, »Gegen den Strom « und die CPUSA . . . . . . . . . . . . . 232

Bek-grans politische Sozialisation . . . . . . . . . . . . . . 232

Im Dienste der Kommunistischen Partei der USA . . . . . . . . . . . . . . . . . . . 233

"Gegen den Strom" . . . . . . . . . . . . . . . . . . . . . . . 236

Der unbekannte Helfer . . . . . . . . . . . . . . . . . . . . 240

VIII. Georg K. Glaser: Die Partei und das Schreiben . . . . . . . . . . . . . . . . 242

Die Kritik einer Erzählung . . . . . . . . . . . . . . . . . . . . . . . . . . 242

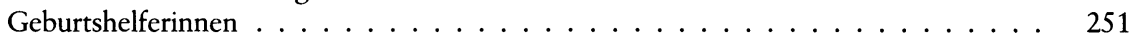

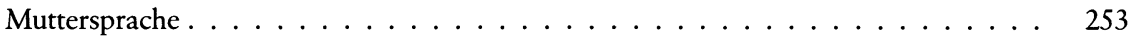

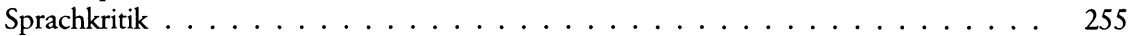

Ablehnung von"Geheimnis und Gewalt" . . . . . . . . . . . . . . . . . . . 257

Autobiographie . . . . . . . . . . . . . . . . . . 259

IX. Stereotypen und Typologie . . . . . . . . . . . . . . . . . . 263

Ontologisierung und Typologie . . . . . . . . . . . . . . . . . . . 263

Der Renegat als "Nihilist" oder"Wahrer Sozialist" . . . . . . . . . . . . . . . . . . 267

Der einsame Renegat. Stalin als Adressat . . . . . . . . . . . . . . . . . . 271

Die Wahrheit . . . . . . . . . . . . . . . . . . . . . . . 274

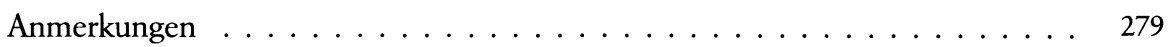

Kurzbiographien . . . . . . . . . . . . . . . . . . . . . . . . 349

Abkürzungen von Periodika . . . . . . . . . . . . . . . . . . . . . . . . . . . . . . . . . . . . . . . . . 362

Abkürzungen von Organisationen . . . . . . . . . . . . . . . . . 363

Bibliographie: Renegatenliteratur . . . . . . . . . . . . . . . . . . . 365

Bibliographie: Sekundärliteratur (einschließlich Belletristik) . . . . . . . . . . . 382

Personenregister ....................... 401 
Mit der Nennung von Autor, Jahr und Seitenzahl wird auf die Bibliographie verwiesen; ausführliche Quellenangabe erfolgt in der Fußnote dann, wenn die Quelle einmalig zitiert wird oder für das Thema marginale Bedeutung hat. Hervorhebungen im Zitat stammen, sofern nicht anders vermerkt, vom jeweiligen Autor. (Meine Einfügungen stehen in eckigen Klammern.) In der Regel wurden Zitate aus dem Englischen und Französischen von mir übersetzt.

Die Siglen von Zeitschriften und die Abkürzungen von Organisationen sind zu Beginn der Bibliographie verzeichnet.

Eingerückte Passagen haben (ähnlich wie einige Fußnoten) die Funktion von erläuternden oder illustrierenden Exkursen. Sie wollen die Argumentation der Arbeit verdeutlichen, die Argumentation sollte aber nicht von ihnen abhängig sein. "In den Fußnoten werden zumeist gerade solche Belege untergebracht, auf die nicht näher eingegangen wird, deren Beweischarakter also noch durchaus fraglich ist «, schreibt Peter Szondi (»Über philologische Erkenntnis«) - mit einigem Recht; sie sind, wie die eingerückten Passagen, die Kompromisse oder Ventile einer geschlossenen Arbeit. 
»(...) und ich bin außer mir, wenn dann andere ihre ahnungslosen Schnäbel daran wetzen, sie, denen alles erspart geblieben ist und die nicht wissen, was sie da eigentlich tun.« Marieluise Fleißer an Arno Schmidt (1965)

»In seinem Versuch, soviel wie möglich über die Sowjetunion zu erfahren, las X von ungefähr 1930 bis 1950 nichts als die Werke angesehener nichtkommunistischer Autoren 〈...〉. Dieses geistige Kraftfutter wurde durch die Lektüre höchst objektiver nichtakademischer Rußlandkenner ergänzt $\langle\ldots .$.$\rangle . Sein Freund Y verspürte die gleiche Wißbegier, aber$ sein Geschmack war auf das Nichtgelehrte und Melodramatische gerichtet. Da ihm Objektivität gleichgültig war, suchte er den Schlüssel zur sowjetischen Politik in den Schriften der geschworenen Feinde des Regimes, wie etwa der Ex-Menschewiki; er genoß die romanhaften Berichte à la Koestler und Victor Serge. Von Stufe zu Stufe sinkend, verschlang Y kitschige oder Sensationsgeschichten der Gattung IIch war Gefangener des roten Terrors . Er versetzte X in Wut, indem er behauptete, manches von der sowjetischen Politik sei leichter zu verstehen, wenn man den Kampf zwischen Al Capone und Dan Torrio, nicht aber den zwischen Lenin und Martow oder die Polemik über Sozialismus in einem Lander studiere. Welcher unserer beiden erdachten Helden wäre besser in der Lage gewesen, das Wesen der sowjetischen Politik unter Stalin zu verstehen? Natürlich ist diese Gegenüberstellung nicht ganz fair. Es gab eine Anzahl wissenschaftlicher Werke, die durchaus realistisch waren und das Kind beim Namen zu nennen wagten. Aber im allgemeinen gilt, daß der durchschnittliche angloamerikanische Gelehrte, der während der in Frage stehenden Periode schrieb, an Kategorien wie >Polizeistaat‘, ,Terror', ,Totalitarismus` mit der gleichen Bangigkeit und demselben Abscheu heranging wie der viktorianische Romancier, wenn er den Geschlechtsakt andeuten wollte..."

Adam B. Ulam (1967) 